“C 2019 IEEE. Personal use of this material is permitted. Permission from IEEE must be obtained for all other uses, in any current or future media, including reprinting/republishing this material for advertising or promotional purposes, creating new collective works, for resale or redistribution to servers or lists, or reuse of any copyrighted component of this work in other works." 


\title{
Key Parameter Design and Analysis of Flux Reversal Linear Rotary Permanent Magnet Actuator
}

\author{
Kaikai Guo, Youguang Guo
}

\begin{abstract}
Flux reversal linear rotary permanent magnet actuator (FR-LRPMA) is a two-degree-of-freedom actuator with two ferromagnetic $(\mathrm{Fe})$ poles and two permanent magnet $(\mathrm{PM})$ poles mounted on the surface of each stator pole. The inductance and flux linkage waveforms of the actuator are more sinusoidal than those of the traditional single topology, which are analyzed by the ideal linear model of one stator section of the proposed actuator. In order to reduce the amplitudes of the cogging torque and detent force, a key space gap parameter of FR-LRPMA between the Fe pole and $P M$ pole is studied in the circumferential and axial directions. The expressions of cogging torque and detent force are derived by the magnetomotive force analytical method, which are used to obtain the optimal space gap parameter value. The electromagnetic characteristics of the actuator are analyzed by the finite element method and the experiment. As a result, the amplitudes of cogging torque and detent force are reduced and the back electromotive force waveform is more sinusoidal than that of the original topology.
\end{abstract}

Index Terms-cogging torque; detent force; finite element method; flux reversal linear rotary permanent magnet actuator; magnetomotive force analytical method.

\section{INTRODUCTION}

$\mathbf{N}$ OWADAYS, linear rotary motor (LRM) has become an important research topic in industrial production, which has attracted the attention of many researchers. A rotary linear switched reluctance motor was presented in [1], and its characteristics were analyzed by 3-D finite element method (FEM). Shodai Tanaka proposed a cross-coupled two-degreeof-freedom (2-DOF) motor with helical windings located in and out the bobbins in [2]. The cogging torque of a 2-DOF cylindrical actuator was reduced by changing the shape of stator and mover salient pole, which combined permanent magnet (PM) rotary synchronous motor and PM linear synchronous motor [3]. In [4], a linear rotary electromagnetic actuator with light-weight moving coil and unique magnetic circuits was presented, and closed-form analytical solutions were used to calculate the magnetic field within the coil operating regions. In [5], an axial double winding LRM was proposed with PM fixed on the hollow shaft. In [6], a rotary-linear voice coil motor was proposed, which can achieve high acceleration and a

Manuscript receipt and acceptance dates will be inserted here. This work was supported by the National Natural Science Foundation of China under Grants 51507051. (Corresponding author: Kaikai Guo.)

Kaikai Guo is with the School of Electrical and Information Engineering, Anhui University of Science and Technology, Huainan, China (e-mail: guokai0072000@gmail.com).

Youguang Guo is with the School of Electrical and Data Engineering, University of Technology Sydney, NSW, Australia (e-mail: Youguang.guo1(a,uts.edu.au)
2-DOF motion. The operating principle and force characteristics of this motor were analyzed and calculated by equivalent magnetic circuit method (MCM) and FEM. In [7][8], two rotary-linear induction motors were presented with rotary and linear-tubular armatures placed side-by-side in the stator. In [9], the operational principle, structural and the characteristics of a transverse-flux-type cylindrical linear synchronous motor were studied by MCM and 3-D FEM. A 2-DOF rotary-linear actuator with a special PM-array and classical windings was described, which was used in robotic applications in [10]. Babak Assadsangabi proposed a rotary linear microactuator, and it was applied to a micro endoscopic catheter in [11]. In [12], a LRM was proposed with a semi-cylindrical rotary motion stator core, a linear motion stator core and a rotor structure. In [13][14], a linear rotary permanent magnet actuator (LRPMA) with interlaced poles and an LRPMA with independent magnetic circuit structure were proposed and the air-gap magnetic flux densities were analyzed by magnetic analytical methods. In [15], an equivalent curvature coefficient method was used to calculate the 3-D air-gap magnetic flux density of a flux reversal linear rotary permanent magnet actuator (FR-LRPMA). In [16], an LRPMA with two sets of spiral winding inside and outside was presented, which can only achieve spiral motion. In [17][18], an LRM with a surface-mounted PM motor structure and a PM gear structure, a hybrid excitation LRM with two independent position detecting coils inserted on the stator and the exciting winding located on the mover were proposed, which can achieve rotary and linear motion independently.

An ideal linear model of stator I is built to analyze the flux linkage characteristic of FR-LRPMA, which is used to deduce the relationship among the stator pole, the mover pole width and the mover pole pitch. In order to achieve the minimum values of the amplitude of the cogging torque and detent force, a space gap parameter between the permanent magnet (PM) pole and the ferromagnetic $(\mathrm{Fe})$ pole is introduced in the circumferential and axial directions. The cogging torque, detent force and back electromotive force (Back-EMF) are analyzed by 3-D FEM. A prototype of FR-LRPMA is manufactured to verify the effect of the space gap parameter value after the optimization.

\section{DESIGN OF FR-LRPMA}

\section{A. FR-LRPMA}

Fig. 1 shows the FR-LRPMA topology with three identical stator sections and two stator magnetic isolation aluminum rings in the axial direction. There are two pole-pairs in the ro- 
tary direction and one pole-pair in the axial direction. Two PM poles and two Fe poles are mounted on the surface of each stator pole. There are eight mover poles in the circumferential direction, which are staggered by 22.5 degrees in the axial direction. The concentrated windings in the stator are used to achieve the linear, rotary or spiral motion. Table I lists the main parameters of FR-LRPMA.

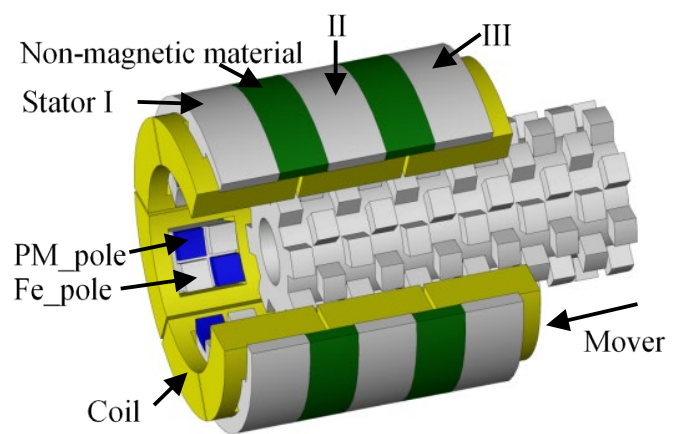

Fig. 1. The topology of FR-LRPMA.

TABLE I

SPECIFICATIONS OF FR-LRPMA

\begin{tabular}{|c|c|c|c|}
\hline Parameters & Value & Parameters & Value \\
\hline Mover radius $\left(R_{r}, \mathrm{~mm}\right)$ & 30.1 & PM height $\left(h_{m}, \mathrm{~mm}\right)$ & 5.2 \\
\hline $\begin{array}{l}\text { Mover pole length }\left(L_{s_{-}},\right. \\
z / \mathrm{mm})\end{array}$ & 7.5 & $\begin{array}{l}\text { Mover pole pitch }\left(\tau_{z},\right. \\
z / \mathrm{mm})\end{array}$ & 21 \\
\hline $\begin{array}{l}\text { Stator pole width }\left(\beta_{\mathrm{s}} /\right. \\
\left.w_{\mathrm{s} \_}, \theta, z / \mathrm{mm}\right)\end{array}$ & 21 & $\begin{array}{l}\text { Ratio of stator pole and } \\
\text { slot }\left(\alpha_{q z}, z\right)\end{array}$ & 1.5 \\
\hline $\begin{array}{l}\mathrm{PM} / \mathrm{Fe} \text { pole width }\left(b_{m \theta},\right. \\
\theta / \mathrm{mm})\end{array}$ & 9.9 & $\begin{array}{l}\mathrm{PM} / \mathrm{Fe} \text { pole length }\left(b_{m z},\right. \\
z / \mathrm{mm})\end{array}$ & 9.5 \\
\hline Mover slot depth (mm) & 8.1 & Winding number & 80 \\
\hline Air-gap length $\left(h_{g}, \mathrm{~mm}\right)$ & 0.6 & Coil diameter (mm) & 0.6 \\
\hline $\begin{array}{l}\text { Ratio of stator pole and } \\
\text { slot }\left(\alpha_{q \theta}, \theta\right)\end{array}$ & 1.2 & $\begin{array}{l}\text { Mover inner radius } \\
\left(R_{r_{-} i n}, \mathrm{~mm}\right)\end{array}$ & 22 \\
\hline Stator length $(z / \mathrm{mm})$ & 97 & Mover length (z/mm) & 144 \\
\hline $\begin{array}{l}\text { Mover pole width }\left(\beta_{r p},\right. \\
\theta / \text { mech. deg. })\end{array}$ & 11.05 & $\begin{array}{l}\text { Mover shaft radius } \\
\left(R_{\text {sha }}, \mathrm{mm}\right)\end{array}$ & 12 \\
\hline $\begin{array}{l}\text { Stator yoke thickness } \\
\left(h_{\text {st yoke }}, \mathrm{mm}\right)\end{array}$ & 5 & $\begin{array}{l}\text { Stator radius }\left(R_{s_{-} \text {out }},\right. \\
\mathrm{mm})\end{array}$ & 60 \\
\hline
\end{tabular}

\section{B. Calculation of the Main Electromagnetic Parameters}

Fig. 2 shows the overview of FR-LRPMA in the circumferential and axial directions. (a)

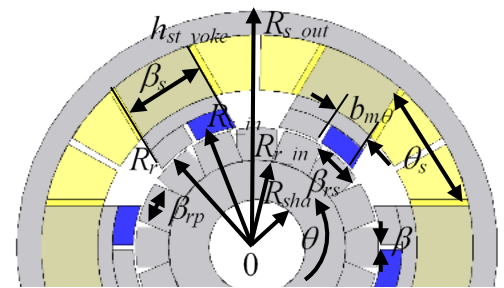

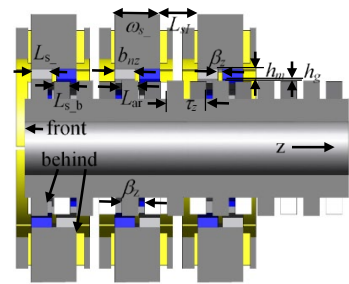

(b)
Fig. 2. The overview of FR-LRPMA in the circumferential and axial directions, (a) circumferential direction, (b) axial direction.

\section{1) Permanent magnet}

According to the design of surface-mounted PM machine, the prediction formula of PM height is

$$
h_{m}=\frac{u_{r} h_{g}}{B_{r} / B_{\delta}-1}
$$

where $u_{\mathrm{r}}$ is the relative permeability of PMs, $\left(u_{\mathrm{r}}=1.0447\right), B_{r}$ is the residual flux density of $\mathrm{PM}$, and $B_{\delta}$ is the average magnetic flux density in the middle position of air gap.

\section{2) The parameters of the stator}

According to the single magnetic circuit of FR-LRPMA, the stator yoke thickness $h_{\text {st yoke }}$ can be found from

$$
2 B_{s_{-} \text {yoke }} p_{\theta} h_{s_{-} \text {yoke }}=B_{\delta} \pi R_{s_{-} i n} \alpha_{q \theta} \frac{\beta_{s}}{w_{s_{-} Z}}
$$

The stator pole widths in circumferential and axial directions can be expressed by

$$
\beta_{s}=\frac{B_{\delta} \pi R_{s_{-} i n} \alpha_{q \theta} \frac{\beta_{s}}{w_{s_{-} Z}}}{B_{t} N_{s \theta}}=\frac{B_{\delta} \tau_{\theta} \alpha_{q z} \frac{\beta_{s}}{w_{s_{-} Z}}}{B_{t}}=w_{s_{-} Z}=2 b_{m \theta}=2 b_{m z}
$$

where $R_{s_{-} \text {in }}$ is the radius of $S_{\text {in_stator }}, B_{s_{-} y o k e}$ and $B_{t}$ are the magnetic flux densities in the stator yoke and the stator pole, respectively, $p_{\theta}$ and $N_{s} \theta$ are the numbers of pole pairs and stator teeth in the circumferential direction, respectively.

\section{The Inductance and Flux Linkage Characteristics Com- parative Analysis}

Considering the dual staggered flux reversal structure in the single stator section, in order to simplify the study, the front part of stator I is taken as an object for analysis in the paper. When $\beta_{s} \leq \tau_{z}, \beta_{r p} \leq \beta_{s} / 2, \tau_{z}-\beta_{r p} \leq \beta_{s} / 2, \beta_{s} \leq \beta_{r p}+\tau_{z} / 2$, Fig. 3 shows the relationship between the winding inductance $L(\theta)$ and the position angle $(\theta)$ of the mover. The permeance difference between the PM pole and Fe pole is ignored. When it is in rotary direction, the stator pole and mover pole keep all overlapping during the region of $\theta_{1 f} \sim \theta_{2} f$. The inductance reaches the maximum value $L_{\max }$, while the phase inductance remains constant. When the mover pole is in the region of $\theta_{2} f \sim \theta_{3} f$, the inductance drops to the minimum value $L_{\min }$. When it is in $\theta_{3} f$ $\sim \theta_{4} f$ region, a mover pole will be away from the stator pole, and the other enters the stator pole gradually, then the inductance is a constant value. When the mover pole leaves the position $\theta_{4} f$, the phase inductance starts to rise. When the mover pole moves to the position $\theta_{5}$, the stator pole and mover pole all overlap, and the inductance reaches the maximum value $L_{\text {max }}$.

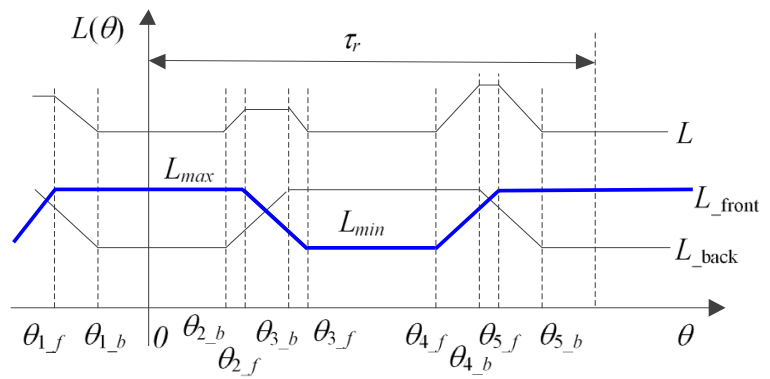

Fig. 3. The relationship between the winding inductance and the position angle of the mover.

where $\theta_{1-f}, \theta_{2} f, \theta_{3} f, \theta_{4} f, \theta_{5} f$ are the coincident positions of the back edge of the mover pole and the back edge of the stator pole, the front edge of the mover pole and the front edge of 
the stator pole, the front edge of the next mover pole and the back edge of the stator pole, the front edge of the first mover pole and the front edge of the stator pole, the back edge of the second mover pole and the back edge of the stator pole, respectively. The expression of the inductance of the stator I front part is

$$
L(\theta)= \begin{cases}L_{\max } \cdot L_{s_{-} f} & \theta_{1_{-} f} \leq \theta \leq \theta_{2_{-} f} \\ {\left[L_{\max }-K\left(\theta-\theta_{2_{-} f}\right)\right] \cdot L_{s_{-} f}} & \theta_{2_{-} f} \leq \theta \leq \theta_{3_{-} f} \\ L_{\min } \cdot L_{s_{-} f} & \theta_{3_{-} f} \leq \theta \leq \theta_{4_{-} f} \\ {\left[L_{\min }+K\left(\theta-\theta_{4_{-} f}\right)\right] \cdot L_{s_{-} f}} & \theta_{4_{-} f} \leq \theta \leq \theta_{5_{-} f}\end{cases}
$$

where $\theta_{1_{-} f}=\theta_{5_{-} f}=\tau_{r}-\left(\beta_{s}-\beta_{r p}\right) / 2, \theta_{2_{-} f}=\left(\beta_{s}-\beta_{r p}\right) / 2$, $\theta_{3_{-} f}=\tau_{r}-\left(\beta_{s}+\beta_{r p}\right) / 2, \theta_{4_{-} f}=\left(\beta_{s}+\beta_{r p}\right) / 2$, $K=\left(L_{\max }-L_{\text {min }}\right) /\left(\theta_{5_{-} f}-\theta_{4_{-} f}\right)=\left(L_{\max }-L_{\text {min }}\right) /\left(\tau_{r}-\beta_{s}\right)$.

The expression of the inductance in single mover pole pitch of the stator I is

$L(\theta)=$

$$
\left\{\begin{array}{lc}
L_{\max } * L_{s_{-} f}+\left[L_{\max }-K\left(\theta-\theta_{4_{-} f}\right) * L_{s_{-} b}\right] & \theta_{1_{-} f} \leq \theta \leq \theta_{1_{-} b} \\
L_{\max } * L_{s_{-} f}+L_{\min } * L_{s_{-} b} & \theta_{1_{-} b} \leq \theta \leq \theta_{2_{-} b} \\
L_{\max } * L_{s_{-} f}+\left[L_{\min }+K\left(\theta-\theta_{2_{-} f}\right)\right] * L_{s_{-} b} & \theta_{2_{-} b} \leq \theta \leq \theta_{2_{-} f} \\
L_{\max } * L_{s_{-} f}+L_{\min } * L_{s_{-} b}-K\left(\theta-\theta_{2_{-} f}\right) *\left(L_{s_{-} f}-L_{s_{-} b}\right) & \theta_{2_{-} f} \leq \theta \leq \theta_{3_{-} b} \\
{\left[L_{\max }-K\left(\theta-\theta_{2_{-} f}\right)\right]^{*} L_{s_{-} f}+L_{\max } * L_{s_{-} b}} & \theta_{3_{-} b} \leq \theta \leq \theta_{3_{-} f} \\
L_{\min } * L_{s_{-} f}+L_{\max } * L_{s_{-} b} & \theta_{3_{-} f} \leq \theta \leq \theta_{4_{-} f} \\
{\left[L_{\min }+K\left(\theta-\theta_{4_{-} f}\right)\right] * L_{s_{-} f}+L_{\max } * L_{s_{-} b}} & \theta_{4_{-} f} \leq \theta \leq \theta_{4_{-} b} \\
L_{\min } * L_{s_{-} f}+L_{\max } * L_{s_{-} b}+K\left(\theta-\theta_{4_{-} f}\right) *\left(L_{s_{-} f}+L_{s_{-} b}\right) \theta_{4_{-} b} \leq \theta \leq \theta_{5_{-} f}
\end{array}\right.
$$

where $L_{s f}$ and $L_{s_{-} b}$ are the inductances of the front and the back of the stator I, respectively.

It can be seen that when the mover pole width is half the stator pole width and the mover pole pitch, namely, $\beta_{r p}$ $=\beta_{s} / 2=\beta_{r} / 2$, the amplitude of the flux linkage reaches the maximum value.

\section{KEY DIMENSIONS OF FR-LRPMA}

Assuming that the permeability of the iron core is infinite, the flux leakage is negligible, the magnetic direction of PM is only in the radial direction, and the Fe pole can be taken as the PM pole in the opposite direction. Fig. 4 is the magnetomotive force (MMF) permeance model of FR-LRPMA, when it is in rotary motion. In the linear motion, the analytical method can be applied in the same way. The position where the left side of the stator is aligned with the left side of the mover is defined as the initial position.

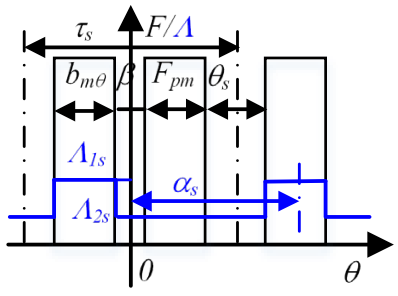

(a)

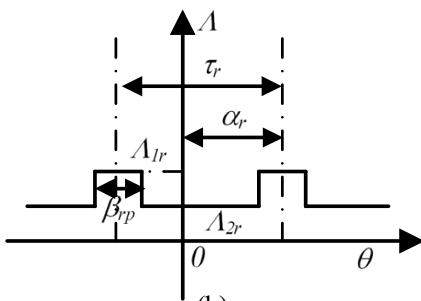

(b)
Fig. 4. MMF permeance model of FR-LRPMA, (a) $F_{\mathrm{pm}} / \Lambda$ waveform, (b) $\Lambda$ waveform of rotor tooth.

According to the MMF permeance model, the expression of the magnetic flux density distributions at no-load condition is

$$
B\left(\theta, \alpha_{r}\right)=F_{p m}(\theta) \Lambda_{s}\left(\theta, \alpha_{s}\right) \Lambda_{r}\left(\theta, \alpha_{r}\right)
$$

where $F_{p m}(\theta), \Lambda_{\mathrm{s}}\left(\theta, \alpha_{s}\right)$ and $\Lambda_{\mathrm{r}}\left(\theta, \alpha_{r}\right)$ are the MMF excited by the PM, air-gap magnetic permeance of stator tooth and rotor tooth, respectively. $\theta$ is the angle in the circumferential direction, and $\alpha_{s}, \alpha_{r}$ are the angles of stator position relative to the initial position, and rotor position relative to $\theta$, respectively.

The expression of the cogging torque is

$$
\begin{aligned}
T_{c o g}\left(\alpha_{r}\right) & =-\frac{\partial W}{\partial \alpha_{r}}=-\frac{\partial}{\partial}\left(\frac{1}{2 \mu_{0}} \int B^{2}\left(\theta, \alpha_{r}\right) d V\right) \\
& =-\frac{\partial}{\partial \alpha_{r}}\left(\frac{1}{2 \mu_{0}} \int F_{p m}^{2}(\theta) \Lambda_{r}^{2}\left(\theta, \alpha_{r}\right) \Lambda_{s}^{2}\left(\theta, \alpha_{s}\right) d V\right)
\end{aligned}
$$

where $W$ is the total energy stored in the air gap, $\mu_{0}$ is the magnetic permeability of free space, and $V$ is the volume of the air gap.

The Fourier expression of the square of MMF drop is

$$
F_{p m}^{2}(\theta)=F_{p m 0}+\sum_{n=1}^{\infty} F_{p m n} \cos \left(n N_{s} \theta\right)
$$

where $F_{p m 0}=N_{s \theta} / \pi F_{p m}^{2} b_{m \theta}$ and

$$
\begin{aligned}
F_{p m n} & =2 F_{p m}^{2}\left[\sin \left(n N_{s \theta} \beta / 2+n N_{s \theta} b_{m \theta}\right)-\sin \left(n N_{s \theta} \beta / 2\right)\right] / n \pi \\
& =4 F_{p m}^{2} \cos \left[\left(n N_{s \theta} \beta+n N_{s \theta} b_{m \theta}\right) / 2\right] \sin \left(n N_{s \theta} b_{m \theta} / 2\right) / n \pi
\end{aligned}
$$

$b_{m \theta}$ and $\theta_{s}$ are the angles of PMs and stator slot in the circumferential direction, respectively.

When the initial position remains unchanged, $\alpha_{s}$ is a constant value. The Fourier expression of the magnetic permeance distribution of stator tooth is

$$
\Lambda_{s}^{2}\left(\theta, \alpha_{s}\right)=\Lambda_{s 0}+\sum_{m_{s}=1}^{\infty} \Lambda_{s m} \cos m N_{s \theta}\left(\theta+\alpha_{s}\right)
$$

The Fourier expression of the magnetic permeance distribution of rotor tooth is

$$
\Lambda_{r}^{2}\left(\theta, \alpha_{r}\right)=\Lambda_{r 0}+\sum_{m_{r}=1}^{\infty} \Lambda_{r m} \cos m_{r} N_{r}\left(\theta+\alpha_{r}\right)
$$

where $\Lambda_{s 0}=N_{s} / \pi \Lambda_{s m}^{2} b_{m \theta}$,

$\Lambda_{s m}=4 \Lambda_{s m}^{2} \cos \left[\left(m_{s} N_{s} \beta+m_{s} N_{s} b_{m \theta}\right) / 2\right] \sin \left(m_{s} N_{s} b_{m \theta} / 2\right) / m_{s} \pi$,

$\Lambda_{r 0}=N_{r}\left[\left(\tau_{z}-\beta_{r \mathrm{p}}\right) \Lambda_{r 2}^{2}+\beta_{r \mathrm{p}} \Lambda_{r 1}^{2}\right] / 2 \pi$,

$\Lambda_{r m}=\left(2\left(\Lambda_{r 1}^{2}-\Lambda_{r 2}^{2}\right) /\left(m_{r} \pi\right)\right) \sin \left(m_{r} N_{r} \beta_{r \mathrm{p}} / 2\right)$,

$m_{r}=k_{r} N_{s} / G C D\left(N_{s}, N_{r}\right), k_{r}=1,2,3 . ., \Lambda_{r 1}, \Lambda_{r 2}, \Lambda_{s 1}$ and $\Lambda_{s 2}$ are the magnetic permeance per unit area for the rotor tooth and slot, the stator tooth and slot, respectively, $\beta_{r p}$ is the angle of rotor tooth, and $N_{r}$ is the number of rotor slots. 
In order to reduce the amplitude of the cogging torque, the specific harmonic component of cogging torque can be eliminated by optimally choosing the value of $\beta$. Let the expression (9) equal 0 , then the analytical value of $\beta$ is

$$
\beta=k_{1} \pi / k_{r} \operatorname{LCM}\left(N_{s}, N_{r}\right)-b_{m \theta}, k_{1}=1,3,5 \ldots
$$

where $\operatorname{GCD}\left(N_{s}, N_{r}\right)$ and $\operatorname{LCM}\left(N_{s}, N_{r}\right)$ are the greatest common divisor and lowest common multiple of $N_{s}$ and $N_{r}$, respectively.

\section{EXPERIMENT AND VERIFICATION}

Fig. 5 shows the Back-EMF waveforms of phase A of the original and improved topologies. It can be noted that the improved topology achieves a more sinusoidal Back-EMF waveform. Fig. 6 is the harmonic analysis result. The fundamental harmonic values of the original and improved topologies are $7.397 \mathrm{~V}$ and $7.705 \mathrm{~V}$, respectively. And it is the largest one of all the harmonic components. It is clear that the space gap $\beta$ can alleviate the pole-to-pole flux leakage in the stator tooth to some extent and it can also help to increase the Back-EMF and reduce the total cogging torque. According to (12), the analytical values of $\beta$ can easily be obtained as $1.2 \mathrm{~mm}$ and $2 \mathrm{~mm}$ in the circumferential and axial directions, respectively.

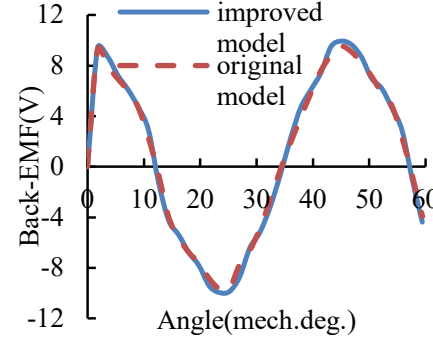

Fig. 5. Waveforms of phase A.

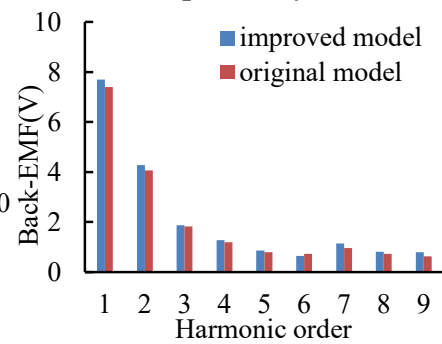

Fig. 6. Back-EMF harmonics.
Fig. 7 shows the Back-EMF waveform of FR-LRPMA calculated by 3-D FEM at the initial position. It can be seen that at the same axial position, the phase difference is $120^{\circ}$ electrical among the three phase Back-EMFs in one set of stators. There is a phase difference $120^{\circ}$ electrical in the phase of the adjacent stator Back-EMF waveform. According to the simulation analysis, the phase difference in the same winding is $90^{\circ}$ in the circumferential and axial directions. Assuming that the initial phase of phase $A$ is $0, \pi / 2$ in the rotary and linear directions, then the initial phases of phases $B, C, D, E, F, G, F, I$ in the rotary and linear directions are $(0,7 \pi / 6),(0,-\pi / 6),(2 \pi / 3$, $\pi / 2),(2 \pi / 3,7 \pi / 6),(2 \pi / 3,-\pi / 6),(-2 \pi / 3, \pi / 2),(-2 \pi / 3,7 \pi / 6)$, and $(-2 \pi / 3,-\pi / 6)$, respectively. Fig. 8 shows the amplitude variation waveform of the nine phase Back-EMFs with the change of the mover in the axial position.

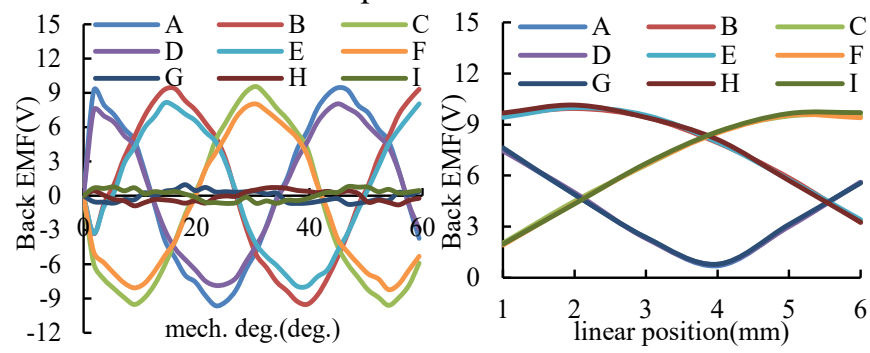

Fig. 7. The waveform of Back-EMF $(L=0 \mathrm{~mm})$ due to rotation.

Fig. 8. The the amplitude variation of Back-EMF along the linear direction.

Fig. 9 shows the prototype of FR-LRPMA, which is used to confirm the effectiveness of the calculation method above. A performance test platform is built, and then the Back-EMF, cogging torque and detent force of the proposed actuator are measured, which are in agreement with those results analyzed by the MMF analytical method and FEM. Fig. 10 illustrates the cogging torque and detent force waveforms of the original and improved actuators, when they are in the initial position. It is clear that the amplitude values of the cogging torque and detent force of the original topology are larger than those of the improved topology, which are analyzed by 3-D FEM. The cogging torque of the improved topology analyzed by 3-D FEM is consistent with the result from the experiment. Since there is a certain error of the machining accuracy of the prototype, the measured result of the detent force is slightly larger than the simulation result. Due to the proper space gap, the cogging torque and detent force of the improved topology are reduced.

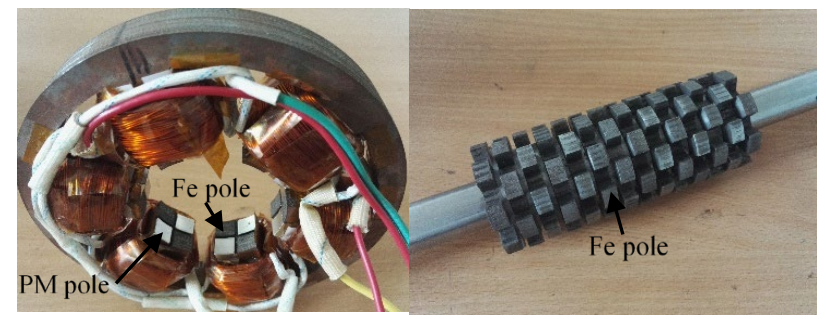

(a)

(b)

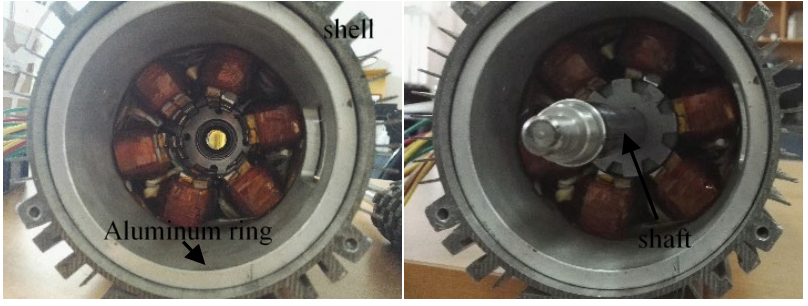

(c)

(d)

Fig. 9. FR-LRPMA prototype, (a) stator I, (b) mover,(c) stator, (d) prototype.

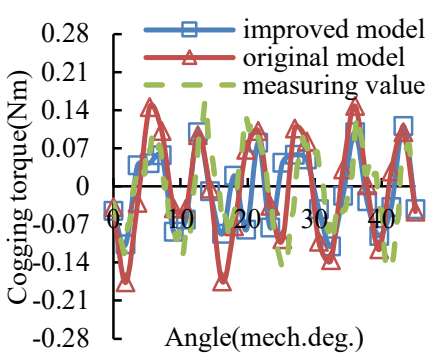

(a)

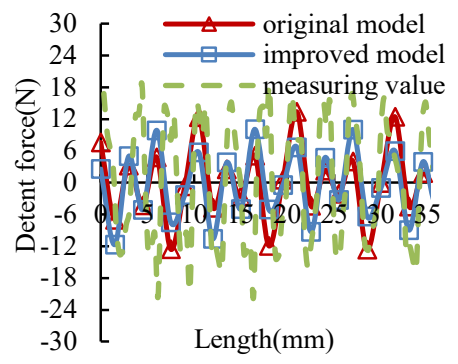

(b)
Fig. 10. Waveforms of cogging torque and detent force by 3-D FEM and experiment measurement, (a) cogging torque, (b) detent force.

\section{CONCLUSIONS}

The main electromagnetic parameters of FR-LRPMA are calculated in the paper, and the inductance and flux linkage characteristics of the front part of stator I are analyzed by building an ideal linear model. It is concluded that the inductance and flux linkage characteristics of the dual staggered flux 
reversal structure are more sinusoidal than those of the single structure. In order to reduce the amplitude of cogging torque, the space gaps between the PM pole and Fe pole in the same stator tooth are considered both in the circumferential and axial directions, and the optimal dimensions are obtained by the MMF analytical model. The amplitudes and initial phases of the nine phase Back-EMF waveforms, which are sinusoidal, change with the axial position of the mover. A prototype is manufactured and the experimental results show that the peak values of cogging torque and detent force are reduced, which also validate the analysis by 3-D FEM. And the Back-EMF waveform of the improved topology is more sinusoidal than that of the original topology.

\section{REFERENCES}

[1] Mohammad Mehdi Nezamabadi, Ebrahim Afjei, and Hossein Torkaman, "Design, dynamic electromagnetic analysis, FEM, and fabrication of a new switched-reluctance motor with hybrid motion," IEEE Trans. Magn., vol. 52, no. 4, Apr. 2016, Art. ID 8201708.

[2] Shodai Tanaka, Tomoyuki Shimono, and Yasutaka Fujimoto, "Optimal design of length factor for cross-coupled 2-DOF motor with Halbach magnet array," in Proc. 2015 ICM, Apr. 2015, pp. 529-534.

[3] Yuki Yoshida, Masaki Mori, Wataru Kitagawa, and Takaharu Takeshita, "Design for cogging torque reduction in two-degree-of-freedom cylindrical actuator," in Proc. 2014 ICEM, Nov. 2014, pp. 478-483.

[4] Tat Joo Teo, Haiyue Zhu, Si-Lu Chen, Guilin Yang, and Chee Khiang Pang, "Principle and modeling of a novel moving coil linear-rotary electromagnetic actuator," IEEE Trans. Ind. Electron., vol. 63, no. 11, pp. 6930-6940, Jan. 2016.

[5] T. T. Overboom, J. W. Jansen, and E. A. Lomonova, et al., "Design and optimization of a rotary actuator for a two-degree-of-freedom z $\phi$ module," IEEE Trans. Ind. Appl., vol. 46, no. 6, pp. 2401-2409, Sep. 2010

[6] Zijiao Zhang, Haibo Zhou, and Ji-an Duan, "Design and analysis of a high acceleration rotary-linear voice coil motor," IEEE Trans. Magn., vol. 53, no. 7, Jul. 2017, Art. ID 8203509.

[7] Ebrahim Amiri, "Circuit modeling of double-armature rotary-linear induction motor," in Proc. 2014-40th IECON, Nov. 2014, pp. 431-436.

[8] Krzysztof Kluszczynski, and Marcin Szczygiel, "How to convert a factory-manufactured induction motor into rotary-linear motor? part 1 constructional issues," in Proc. 2017-15th REM, Sep. 2014, pp. 1-6.

[9] Jung-Seob Shin, Ryuji Watanabe, and Takafumi Koseki, et al., "Transverse-flux-type cylindrical linear synchronous motor for large thrust using generic armature cores for rotary machinery," IEEE Trans. Ind. Electron., vol. 61, no. 8, pp. 4346-4355, Jul. 2013.

[10] K. J. Meessen, J. J. H. Paulides, and E. A. Lomonova, "Analysis of a novel magnetization pattern for 2-DOF rotary-linear actuators," IEEE Trans. Magn., vol. 48, no. 11, pp. 3867-3870, Oct. 2017.

[11] Babak Assadsangabi, and Kenichi Takahata, "Micro rotary-linear actuator assisted by ferrofluidlevitation for 3-dimensional endoscopic imaging," in Proc. 2015 18th ICSSSAM, Aug. 2015, pp. 391-394.

[12] Jikai Si, Lujia Xie, Wenping Cao, Yihua Hu, and Haichao Feng, "Performance analysis of the 2-DOF direct drive induction motor applying composite multilayer method," IET Electric Power Applications, vol. 11, no. 4, pp. 524-531, Apr. 2017.

[13] Kaikai Guo, Shuhua Fang, Heyun Lin, Yunkai Huang, Yang Zhang, and Hui Yang, "A linear-rotary permanent magnet actuator with independent magnetic circuit structure," IEEE Trans. Appl. Supercond., vol. 26, no. 7, Aug. 2016, Art. ID 2603005.

[14] Kaikai Guo, Shuhua Fang, Hui Yang, Heyun Lin, and S. L. Ho, "A novel linear-rotary permanent-magnet actuator using interlaced poles," IEEE Trans. Magn., vol. 51, no. 11, Jun. 2015, Art. ID 8207004.

[15] Kaikai Guo, Shuhua Fang, Heyun Lin, Hui Yang, Yunkai Huang, and Ping Jin, "3-D analytical analysis of magnetic field of flux reversal linear-rotary permanent magnet actuator," IEEE Trans. Magn., vol. 53, no. 6, Feb. 2017, Art. ID 8202205
[16] Ahmad Zaki Shukor, and Yasutaka Fujimoto, "Direct-drive position control of a spiral motor as a monoarticular actuator," IEEE Trans. Ind. Electron., vol. 61, no. 2, pp. 1063-1071, May 2014.

[17] Siavash Pakdelian, Yateendra B. Deshpande, and Hamid A. Toliyat, "Design of an electric machine integrated with trans-rotary magnetic gear," IEEE Trans. Energy Convers., vol. 30, no. 3, pp. 1180-1191, Apr. 2015.

[18] Hiroki Tsujimoto, Shodai Tanaka, and Tomoyuki Shimono, et al., "Design and analysis of a resolver for 2-DOF tubular motor," in Proc. 2016-42nd IESAC, Dec. 2016, pp. 6169-6174. 